\title{
How Can We Ameliorate the Role of Colorectal Cancer Awareness Month?
}

\author{
Weon-Young Chang \\ Department of Surgery, Jeju National University School of Medicine, Jeju, Korea
}

\section{See Article on Page 184-189}

Since 2007, September has been Colorectal Cancer Awareness Month, which has been sponsored by the Korean Society of Coloproctology (KSCP) to raise awareness of colorectal neoplasms [1]. A significant increase was seen in the percentage of informationsharing tweets from $77.1 \%$ to $81.1 \%(\mathrm{P}=0.045)$ during the 2014 Colorectal Cancer Awareness Month. In addition, most of the Korean tweets seen during that month regarding colorectal cancer were commercial spam tweets, with informative public tweets accounting for an extremely small percentage $[2,3]$.

According to the Survey on the Internet Usage 2015 conducted by the Korea Internet \& Security Agency, "out of the social networking services (SNS) users ages $6+, 90.1 \%$ access SNS 'at least once a week' ('at least once a day' $51.8 \%$, 'at least once a week' 38.3\%) for personal purposes." The 2015 Survey on the Internet Usage by Korea Internet \& Security Agency also showed that although the most frequent reason for using SNS is 'to socialized and associate (77.2\%)', users also use SNS 'to share information and knowledge (36.6\%)' [4]. In addition to the increasing rate of internet usage, the rate of people aged 50 and older who must be screened for colorectal cancer screening has increased phenomenally from $5.7 \%$ in 2000 to $89.3 \%$ in 2015 [5]. In this context, this research is important because it evaluates the transmissibility of Colorectal Cancer Awareness Month and proposes roles that the KSCP can use to connect with the millions of peoples using SNS. We expect subsequent research to overcome some of the limitations mentioned in this study.

Ultimately, the KSCP has to contribute to public health by mak-

Correspondence to: Weon-Young Chang, M.D.

Department of Surgery, Jeju National University School of Medicine, 102,

Jejudaehang-ro, Jeju 54987, Korea

Tel: +82-64-754-8101, Fax: +82-64-754-8004

E-mail: orkorea@jejunu.ac.kr ing available to the public the knowledge accumulated through the research efforts of its members. The KSCP should constantly strive to find effective methods to convey that knowledge to those who need it. If Colorectal Cancer Awareness Month is to be an effective means for conveying such knowledge, we need to ameliorate methods, such as social network services, that can increase the transmissibility of this event.

\section{CONFLICT OF INTEREST}

No potential conflict of interest relevant to this article was reported.

\section{REFERENCES}

1. The Korean Society of Coloproctology [Internet]. Seoul (KR): The Korean Society of Coloproctology; c2005 [cited 2016 Oct 20]. Available from: http://www.colon.or.kr/colonlife/info/index. kin?gubun=2\&subid=1.

2. Park S, Oh HK, Park G, Suh B, Bae WK, Kim JW, et al. The source and credibility of colorectal cancer information on twitter. Medicine (Baltimore) 2016;95:e2775 [Epub]. http://doi.org/10.1097/ MD.0000000000002775.

3. Lee KC, Oh HK, Park G, Park SH, Suh B, Bae WK, et al. Transmissibility of the campaign for colorectal cancer awareness in Korea among twitter users. Ann Coloproctol 2016;32:184-9.

4. Korea Internet \& Security Agency. 2015 Survey on the Internet usage [Internet]. Seoul (KR): Korea Internet \& Security Agency; c2015 [cited 2016. Oct 20]. Available from: http://isis.kisa.or.kr/ board/?pageId $=060300$.

5. Korean Statistical Information Service. Survey on the Internet usage [Internet]. Daejeon (KR): Statistics Korea; c2015 [updated 2016 Jan 27; cited 2016 Oct 20]. Available from: http://kosis.kr/statHtml/ statHtml.do?orgId=127\&tblId=DT_MH001_MI003\&conn_ path=I2. 